\title{
[Commentary] Adversarial Leadership in the Data Era
}

\author{
David Graham ${ }^{1}$ \\ 1 University College Dublin
}

Funding: The author(s) received no specific funding for this work.

Potential competing interests: The author(s) declared that no potential competing interests exist.

\section{Abstract}

The world has changed significantly since the day I was born. One could argue that its fantastic political, moral, philosophical, and environmental gyrations have led to an inevitable collision between what is absolute and that which is not. Added to this widening gyre is the fundamental role of data and information in seating emperors on their respective thrones. The shift of power away from the halls of legislature and the proletariat into the hands of the emerging data bourgeoisie has led to the need for a new type of leadership, focused on using the prevalence of data in adversarial ways to shape society (and indeed the world) in new ways.

The world has changed significantly since the day I was born. One could argue that its fantastic political, moral, philosophical, and environmental gyrations have led to an inevitable collision between what is absolute and that which is not. Added to this widening gyre is the fundamental role of data and information in seating emperors on their respective thrones. The shift of power away from the halls of legislature and the proletariat into the hands of the emerging data bourgeoisie has led to the need for a new type of leadership, focused on using the prevalence of data in adversarial ways to shape society (and indeed the world) in new ways.

Adversarial leadership can be construed as being a negative trait or characteristic. In most cases, however, "adversarial" is conflated with "antagonistic." The two couldn't be further from each other in their actions. When we look at adversarial leadership, we look to cases like that of Edward Snowden or Julian Assange, who, while relegated to their respective hiding places in Russia and the Ecuadorian embassy, utilised data as tools to unseat or unsettle society. One could argue that their motives weren't altruistic (in the sense that they also chose the role of antagonist to the United States government), but the net result was awareness; awareness of data collection principles, bad actors that were using this data to repress or oppress marginalised communities, and so on. Ideologically, they showed this concept of adversarial leadership: that is, using tools, data, or policy in ways that countermands the original intent or design to create leverage or opportunity.

What lessons can we learn from these adversarial leaders, then, that can be applied to our more hyper-local circumstances? First, we need to act like everything we do is being recorded Understanding that the role of data is to describe or capture the moments of its creation, we need to be aware of how our actions are being mirrored digitally. When we critically examine Edward Snowden's role in unveiling the data collection policies of the United States' 
intelligence agencies, we become aware that most everything we do is being recorded in some way, shape, or form. This leads to our second lesson: take control of our data. When we understand the first lesson, we then have the unique opportunity to control the method in which our data is being delivered. There are a myriad of tools available and designed to obfuscate, block, or randomize the data that is collected from us. The "right to be forgotten" is a misnomer as far as it relies on the primary actors (us) to take control of our digital agency. In this, our second lesson leads to the third: use your data to create opportunity. Too often we forget that services like Facebook, Walmart, Amazon, Tesco, et al rely on data to gain market advantage. In this, we also forget that we, as the consumers, are at the disadvantage when our data is being used. Efforts to economically commoditise this data to the benefit of the consumer have routinely fallen away leaving, as a result, the nakedness of gross capitalism. When we talk about using our data to create opportunity, we are forcing the locus of control to shift to us, our communities, our members and away from those who would look to use it for their own gain. We can command a social destiny far removed from the desperate march towards global irresponsibility that we find ourselves in today.

Leadership, adversarial or not, is a function of knowing place and purpose. In this, becoming adversarial is nothing more than asserting the place and purpose for which we understand ourselves to best suited for. We have the capabilities and tools in this century to make the necessary changes to our society if only we choose to. This, then, is the lesson for all of us: become leaders by being adversarial. 